\title{
GENESIS OF SOCIAL MEDIA AND THE NATURE OF ITS USERS
}

\author{
Dr. Azam Jan \\ Assistant Professor \\ Department of Communication \& Media Studies \\ Hazara University \\ Mansehra - Pakistan \\ azamjancms@gmail.com \\ Tariq Anwar Khan \\ Lecturer \\ Department of Political Science \\ Hazara University, Mansehra
}

PhD Candidate, Department of Political Science, University of the Punjab, Lahore tariqanwar84@gmail.com

\author{
Dr. Muhammad Imran Mehsud \\ Assistant Professor \\ Department of Political Science and International Relations \\ Hazara University \\ Mansehra - Pakistan \\ muhammadimran@hu.edu.pk
}

\begin{abstract}
The emergence of Social Media (SM) has changed communication behavior of the users. People who used to look forward to traditional mass media for satisfaction of certain needs have switched over to SM for their needs gratification. This paradigm shift forced researchers to undertake studies to find out consumption styles and corresponding effects. This research paper is an effort to reckon with in the arena of research on digital media. The study analyzes origin of SM, various definitions of SM, types of social networking sites, nomenclature of SM, and nature of SM users. New digital technologies are the media that want the users to be social as the nomenclature indicates. Likewise, with regard to the nature of social media users, it was argued that the people born during the decade of 1980s are known as net generation. This generation is however, named differently in different researches such as "Net Generation," the
\end{abstract}




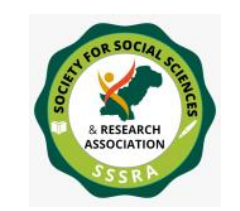

Pak. Journal of Int'L Affairs, Vol 4, Issue 3 (2021)

Genesis of Social Media and the Nature ...

"Net- Gen," "Generation I," the "Digital Generation," or the "Millennial". Hence, the young people have easily adapted to and have more know-how of using digital media than their seniors with respect to age. This generation gap in terms of usability of internet is phrased as the "generational digital divide" or the "generational divide.

Keywords: Genesis, Social Media, Nature of users, Nomenclature, Digital Generation.

\section{Introduction}

The introduction of Social Networking Sites (SNSs) in the latter part of 1990s as means of instant transmitting of digital information has added a new dimension to information dissemination process. This development in turn changed the complexion of communication behaviour of people all over the world. The sharing of self-generated contents through SNSs like Facebook, Twitter etc. and the exchange of photos and audio/video by making use of Flicker, YouTube etc. has converted the traditional mass media function of one way flow of information to two-way traffic of communication. The so called lopsided flow of information of traditional mass media has given way to horizontal flow of exchange of contents through Social Media. This phenomenon shifted the loosely bridged relationship between top media management of traditional mass media to that of very intimate relationship among the users of social networking media. Exiting friendships have been strengthened and new relationships have been established even with people far away from each other (Williams, Crittenden, Keo, \& McCarty, 2012). People involved in communication through social media are very often unfamiliar with respect to offline connections. They belong to different regions, different cultures, different socio-political environments, different religions, different languages and different economic and educational backgrounds. By using social media, these heterogeneous people interact with each other with much ease and convenience. They feel as at home in online situations as they normally do with familiar people around them in real life situations (Bryer \& Zavatarro 2011). When the first SNS was introduced towards the end of the 1990s, it was unimaginable that this tiny plant would nurture into such a huge tree of millions of branches but it has turned to be a reality and now the number of SNSs have increased manifold (Pempek, Yermolayeva, \& Calvert, 2008).

The number of users is estimated to be one billion and it is anticipated to get double in the next decade, particularly in developing countries (Packard 2010). It took seven years to realize Packard's prediction when Miniwatts (2017) estimated the number of internet users in the world as 3.73 billion. Initially, people started using SNSs by making use of computers. Only those having their own PCs and allied facilities benefited properly from 


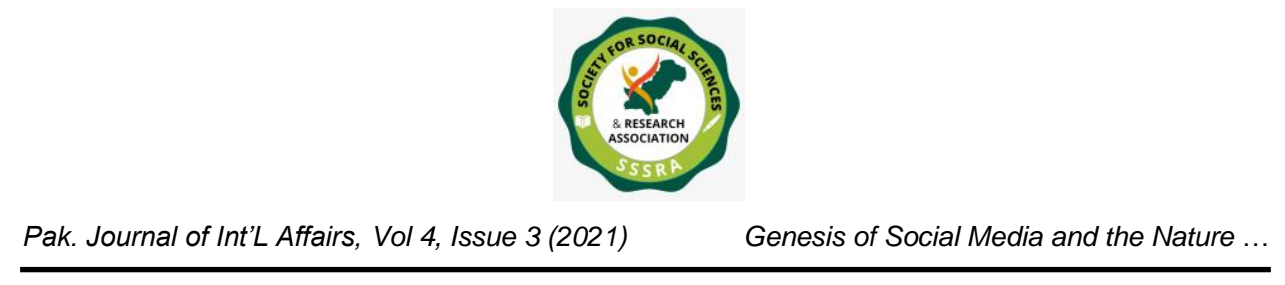

this new technology. The introduction of laptops increased the number of social media users to a substantial level. However, the introduction of smart phones brought tremendous revolution in the usage pattern of this new technology. Now almost every individual with a smart phone has the facility of going online and making use of this digital technology to his/her advantages or otherwise depends on user's temperament (Uricchio 2009).

To have better understanding of the problem under research, a systematic approach has been adopted for discussion of relevant literature to this study. The scheme laid down for this study encompasses literature on 'Genesis and Nomenclature of Social Networking Media', 'Forms \& Types of Social Networking Sites' and 'The Nature of Social Media Users'.

\section{Genesis and Nomenclature of Social Networking Media}

The introduction and subsequent importance of Information and Communication Technology (ICT) cannot be narrated better than Boomen, Lammes, Lehmann, Raessens, \& Schafer (2009). They state:

“The 1982 Time magazine's 'Man of the Year' election was a special one. For the first time in the history of this traditional annual event, a nonhuman was celebrated: the computer was declared 'Machine of the Year 1982'. The cover displayed a table with a personal computer on it, and a man sitting passively next to it and looking rather puzzled. On the 2006 Time's election cover once again a computer was shown, now basically a screen reflecting the 'Person of the Year': 'YOU. Yes, you. You control the Information Age. Welcome to your world."

The origin of this new technology and its close intimacy with human being is considered to be a revolutionary change in human social lives. The computer was no doubt a wonderful machine, but the emergence of SNSs in 1997 added a new dimension to this technology. The interaction of users with other users and with that of its producers contributed a lot to its growth. The facility of interactivity on SNSs led this technology far advanced from those of its predecessors like radio and television. The users of this digital technology made use of it for multifarious purposes like communications, social interaction, business transactions, and participation in political campaigns and discourses.

\section{Defining Social Media}




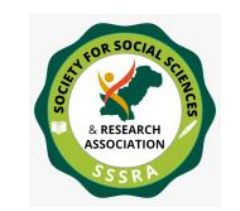

Pak. Journal of Int'L Affairs, Vol 4, Issue 3 (2021)

Genesis of Social Media and the Nature ...

Martin \& Erickson (2013) while defining social media state "websites build on Web 2.0 technologies to provide space for in-depth social interaction, community formation, and the tackling of collaborative projects". Web 2.0 technologies are generally called as "social networking sites, blogs, wikis and virtual communities" (Brown \& Adler, 2008). It is also called as new media or digital media or social networking media or social networking sites (SNSs). All forms of SNSs like Facebook, Twitter, LinkedIn, and YouTube are basically the extension of internet applications with volumes of contents available on their interfaces. The user can also contribute their self-produced stuff and upload the same on any one of these sites. These contents are always available for the comments of other users. This pattern develops a serial of discussion on different topics leading the users to connect with each other. SNSs include a variety of online information that spring from different sites. These contents are created, distributed and in turn used by users for educating one another about new products and ideas (Murugesan, 2007). The users of SNSs generally make a profile by uploading personal details and a picture. The users thus start identifying other users by clicking on their profiles and thus their circle of friends increases. This number gets multiply when the users start clicking those profiles associated with their friend's profiles. The availability of lots of information led the users to share the same with each other for mutual guidance and awareness in respect to matters of mutual interests (Boyed \& Ellison 2007).

\section{Genesis and Nomenclature}

The birth of ICT and the switch over of the world societies from analogue media to new digital media has become the center of all debates in this domain. The new technology is termed by most of the researchers as social media and they have many reasons to call it so. For example Uricchio (2009) believes that turning to digital communications from that of analog, from top-down and vertical to way of interaction among users themselves, from mere information dissemination to analyzing and generation of contents by users, can be termed as a technology that is social by virtue of its design and not by default. Uricchio (2009) was emphazing on the peer to peer interaction through the usage of SNSs. As against traditional mass media where information and contents flow from producers of the contents to consumers of the contents, information flow on social media is horizontal which flows from consumers to consumers. Although some of the contents are there from the producers of the technology but still they flow in horizontal fashion as all users of the technology are considered to be peers (Uricchio p. 136).

Adding to this, Safko (2012) believes that, new digital technologies are the media that want the users to be social as the nomenclature indicates. According to Safko, the first word 'social' in the term "social media" denotes the basic human need of interaction with 


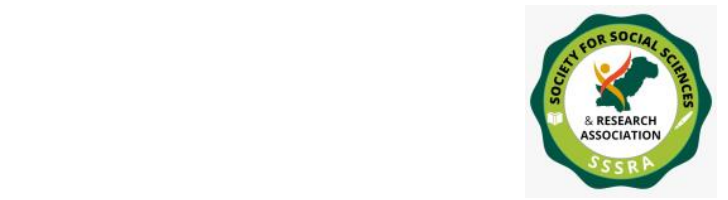

Genesis of Social Media and the Nature...

other human beings. The second word in the terminology indicates the channel through which interactions with other individuals are made. Thus the main aim of the terminology of 'social media' is to make use of the technology for effective connections with others and subsequent creation of relationships among like minded people. Their number sometimes reaches to billions. Besides sharing their personal information with each other, the users often share comments on issues of mutual interests, share texts, do reviews of different contents, distribute photos and audio/video files for different academic and professional purposes (Safko p. 39).

Some researchers have termed social media as 'new media' because it has created a new and a different kind of universal phenomenon. Every aspect of this phenomenon according to them is new. The experience of extent messaging is totally new as it was lacked in the traditional mass media; the relationship between the source (new technology) and the receivers (users) is different to that of the main stream media. Similarly, social media ensures an active relationship within the users themselves, which is lacking within the anonymous receivers of customary media of radio and television (Lister, Dovey, Giddings, Grant, \& Kelly 2009).

As against one way flow of information of traditional mass media, social media ensures two way and many to many way of information trafficking. This new media spontaneously ensure one to one, one to many and many to many communication in the form of text messaging, photo sharing and video sharing (Boyd \& Ellison, 2007).

In the traditional media systems, consumers make use of the contents made solely by the people at the helm of affairs of the respective media channels whereas in social media settings; the users make use of self-generated information and contents and share the same horizontally within no time. But when it comes to virtual and real life situations the tables are turned around as some of the researchers in the field like Bargh \& McKenna (2004) believe that social media develop an "impoverished and sterile form of social exchange compared to real life face-to-face interactions."

Castells (2001) states that "technological systems are socially produced and that social production is culturally informed." In other words, the culture of the people who developed the technology of internet greatly influenced the medium. McLuhan (1964) took inspiration from the emergence of satellite technologies and proposed the concept of "global village" where people across boundaries and cultures can connect with each other. The contemporary thinkers of social media arena considered McLuhan's proposition as a prediction of the emergence of internet technology. 


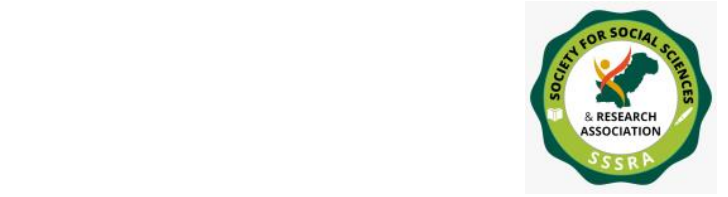

Genesis of Social Media and the Nature ...

A phenomenal fact about SNSs is the change and improvement in their interfaces which results in up gradation of their comparative popularity graph. Innovations have been made from time to time to make different features of SNSs very attractive. Henceforth, catch thousands of new users on daily basis around the world. The users of these sites continuously interact with each other for sharing information and exchange of ideas. This social networking through online sources is believed to be a potent driver of the users generated contents and their mutual linkages. But another fact associated with the usage of SNSs is irreversible and that is its ever lasting effects. The socio-political and psychological effects on the users and on societies are continued to be associated with persistent usage of these sites (Luo 2007).

SNSs are very economical and in many cases are almost totally free to use. That is why billions of users around the world communicate with each other through these sites. This approach implies to the linking of this technology with the communication behaviour of the people. According to this approach people make use of SNSs not only to satisfy their respective information needs but also make use of the technology to establish relationships through sharing of contents and exchange of ideas (Williams et al., 2012). Some other researchers also have the same notions about the usage of these sites. Bryer \& Zavatarro (2011) noted that SNSs help facilitate social linkages among users across frontiers through exchange of information, ideas, thoughts, photos and audios/videos. The cross borders and cross cultural associations of people through these platforms have grown tremendously. This growth of SNSs in the last twenty years in turn has contributed a lot to increasing social networks of the people further (Mehmood 2013; Smith \& Rainie 2008).

There are thousands of SNSs around the world catering to different needs of the users. Every site has its own special features and specifications for attracting as much users as possible. Innovations are made in the features of these sites from time to time to meet the users' needs and requirements. Some of the popular social media forms and sites are listed in the following lines.

\section{Forms \& Types of Social Networking Sites}

Martin \& Erickson (2013) have mentioned the following forms of SNSs:

Blogs: Blogs are the most known forms of social media. They are much like online journals. The most recent entries appear first in the blogs list. People have made it a habit of turning to blogs when they have something to say. The people by making use of blogs contribute their own creations in line with some issue or topic of public interests. 


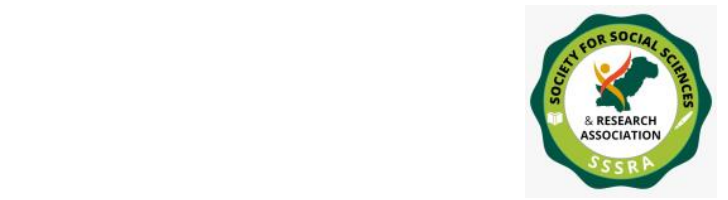

Genesis of Social Media and the Nature...

Wikis: These sites normally act as a database and let users add or edit content on them. Volumes of contents with regard to almost all disciplines, all walks of life and different fields of knowledge are kept on the wikis and are made available to all users. The users generally search contents of their interests by entering the names of the files, works, authors and contributors. The most popular among these is Wikipedia. It is considered as the online encyclopedia with more than two million articles in English language.

Podcasts: these are audio and video files which have been uploaded and stored by individuals and organizations and made available for users but normally on subscription. Forums: Forums generally provide platforms for online discussion and debates on the topic of community specific interests. Forums came into use before the concept of SNSs. They are reckoned as very effective and popular element of online communities.

Micro blogging: It is a form of social networking through "bite-sized blogging, where small amounts of content are distributed online and through the mobile phone network." Hindman (2009) termed "news blogging as citizen journalism and framed as a nonhierarchical revolution in information-sharing."

\section{Types of Social Networking Sites}

\section{Facebook}

The emergence of SNSs facilitated social interaction further by connecting millions of users of all ages and from every nook and corner of the world. Among these sites, Facebook is the most popular site around the globe (Kirschner \& Karpinski 2010; Hargittai 2008; Haq \& Chand 2012). It has been found that $97 \%$ of the internet users make use of SNSs with around 90\% of them using Facebook (Smith \& Rainie 2008; Australian Psychological Society 2010; Haq \& Chand 2012). The popularity of Facebook can be ascertained from its rapid growth in the number of consumers. It was estimated that until 2009, the number of active users of Facebook were crossing over 90 million (Hendrix, Chiarella, Hasman, Murphy, \& Zafron, 2009). The number of Facebook users rose to 250 million in 2011(Connolly's 2011), 800 million in the early part of 2012, 955 million till June 2012 (Safko 2012). The worldwide monthly active users of Facebook reached to 1.94 billion in the first quarter of 2017 (Facebook, March 2017).

The site has deeply diffused into humans' social lives, especially, the young folk (Debatin, Lovejoy, Horn, \& Hughes, 2009). It has been observed that the very first page of the interface of Facebook includes identity features like photographs of the users and 


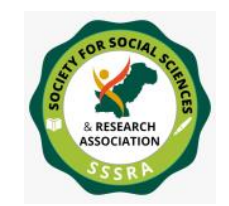

Genesis of Social Media and the Nature...

their linkages with other Facebook users. These facilities are provided to the consumers by the designers of the site to make its usage easy and attractive. The users before using the site upload a profile photo as representative of their identity. Whenever the users do certain activities on Facebook like posting comments, clicking the "like" or "unlike" buttons for some statuses or pictures or audios/videos, their profile pictures appear sideways. Profiles, usually offer two different spheres to the user from where the user can communicate with others. One is a private sphere, from where the user can send and receive private online messages like that of emailing system. The other is a public sphere named as the "Wall." On the wall one can get comments left by his/her friends. These comments on the walls are open and can be watched and read by other users as well. Another feature on the interface of Facebook is "News Feed." This feature keeps the users abreast of what is happening in their social circle. News Feed generally provides fresh information on the activities of the friends. Whenever the users open their Facebook accounts, they are welcomed with fresh and updated stuff about their social networks (Pempek, Yermolayeva, \& Calvert, 2009). If a person's profile is on her/his real name, s/he will make sure to provide clear cues to be easily identified by others. This practice enables users to identify each other by looking at each other profiles. They normally do it by searching registered members or requesting their friends by e-mail to join Facebook. After accepted as friends, their profiles along with the whole 'network' are disclosed to each other. This in turn let the users to navigate networks by searching friend's profiles, allowing one's social network to manipulate quickly (Walther, et al., 2008; Ahn 2011).

In a study of the analysis of profiles and user's behaviour on "Facebook, LinkedIn, and "Asmallworld", Papacharissi (2009) found that the relationship between the features, standards and aims of every SNS and the user's behaviour is very complicated in nature. Facebook according to the study offers comparatively more freedom with regard to membership, communication with each other and disclosure of information. LinkedIn is also wide open network but the format of profile suites the business class membership.

Facebook was founded in Harvard University by Mark Zuckerberg and his colleagues in 2004 as a network for students to connect with their friends around the campus but it was spread over the population across the globe within no time (Abdulahi et al., 2014).

The provision of freedom expression is one of the positives of this site. However, some users share very belittling stuff relating to some political leaders, religious figures and showbiz celebrities. Similarly, in the comments corner one can see heaps of non-sense and ridiculous comments on different issues. As majority of the users comment from their fake identities so they freely and directly target certain religions, religious sects, ethnic groups, minorities, races, and political parties. 


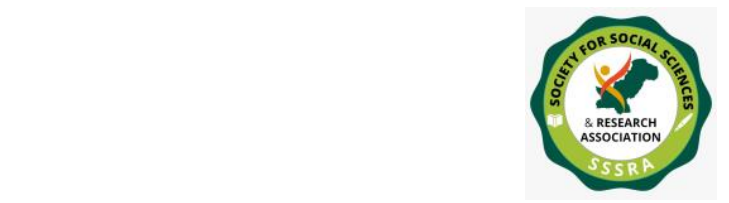

Genesis of Social Media and the Nature...

\section{Twitter}

Twitter is also known as micro blogging site. It is counted as second in popularity among the youth across the globe after Facebook (Connolly, 2011). The characteristic of short messaging of up to one hundred and forty characters sent via Twitter is known as "Tweets" whereas the responses received through Twitter are known as "Re-Tweets" (Moody, 2010). The consumers who have subscribed to receiving tweets are known as followers. Here goes the statement of the Twitter's founder Dorsey (2007) with respect to its popularity as quoted by Kerr; "one could change the world with one hundred and forty characters" (Kerr, 2010).

One of the important features of the Twitter is that highly rated celebrities in every walk of life mostly make use of this site to reach out its fans and discuss issues of common interest. As noted by Kwak, et.al. (2010), more than $85 \%$ of the topics that are discussed by the users on Twitter are abstracted from major news or follow up stories. Affirming this, Moody has aptly noted that the provision of links to burning stories and key sites is one of the distinguishing characteristics of this micro blogging site (Moody 2010).

The contributions of Twitter with respect to nourishing the popular culture and providing platform for citizen journalism are very laudable. To ensuring a number of features and facilities for gratification of its consumers' needs and its diffusion in all facets of life, make twitter an attractive topic for research.

\section{YouTube}

YouTube is one of the most attractive sites for people, particularly, the young generation. Availability of lots of visual contents in the form of movies, videos, documentaries, TV clips and many more make it easily digestible for the users. Another feature that makes YouTube fascinating for youth is provision of sharing domestically generated visual contents. People have made it a habit of uploading each and every video that has been self-produced.

YouTube is basically a video sharing site but Boyed and Ellison (2007) included it in the list of social networking media. YouTube according to Lange has been widely used to privately share videos on the issues of public concern mainly for attracting people and getting popularity among the users. These users however, rarely share the videos concerning their personal lives. Sharing of such videos is often restricted through privacy setting to be viewed only by close circle of friends (Lange, 2007). 


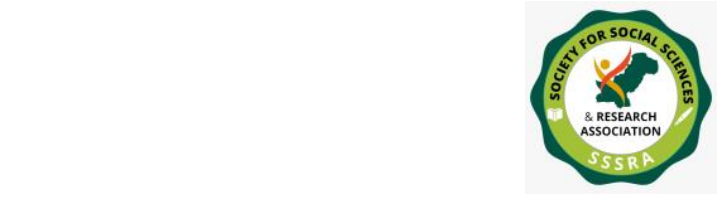

Genesis of Social Media and the Nature...

YouTube is believed to be the largest video sharing machine around the globe. More than 100 million videos are daily watched by people all over the world. Members of YouTube can upload videos or create their own "channels" of favourite videos. The members also upload videos made of their own cameras or cell phones and short clippings taken from television programs. Connolly (2011) found that the users view over two billion YouTube videos daily. In an average hour, the users of YouTube upload 24 hours of video stuff. YouTube commenced functioning as an insignificant private enterprise, but was sold to Google Corporation for \$ 1.65 billion in October 2006 (Martin \& Erickson 2013. P. 23).

\section{LinkedIn}

LinkedIn is one of the world's largest professional networking sites. It is open to all networks but the format of profile suites the business class membership. LinkedIn is normally connecting workers, clients and contenders through its social networking facility. Whereas majority of the users of LinkedIn are one way or the other associated with some sort of commercial enterprise or having interests in some sorts of business dealings (Papacharissi 2009). Linked have 120 million users across the world (Safko 2012, P. 30).

The site is used as a mean of getting assistance with regard to professional networking, career building and seeking an appropriate role. The LinkedIn let its users to form professional profiles which in turn help them link with each other for searching and sharing contents and career prospects. This social networking site allows its users to brand themselves according to their field of interests or specializations. Branding generally aims at giving an impression of one's expertise, specialties and skills in the relevant field. The users of LinkedIn usually interact and communicate with each other as members of different professional groups for extending or getting support in line with their profession. Though interaction through LinkedIn is wide-open but users generally post contents about their profession and interests. The users of LinkedIn avoid posting everything they have in their mind as they do while using other sites such as Facebook.

Another area of literature reviewing that is deemed necessary is giving an insight into the nature of the youth born in the digital age. This area was found important on the ground that the young generation is one of the key stalk holders in this research work with respect to their heavy usage of social media.

\section{The Nature of Social Media Users}




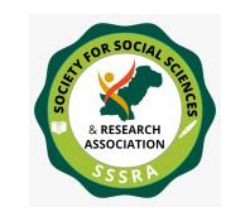

Genesis of Social Media and the Nature...

People born in the 1980s and 1990s can be termed as 'Net Generation' just because of their media consumption, particularly social media consumption behaviour. These people have the inclination to adapt to every new technology more swiftly than their predecessors. They usually get themselves engaged round the clock using almost all forms of electronic media for interaction and entertainment. They have been witnessing innovations in the arena of ICT since they came into existence in this world. Today, they make use of SNSs for communication, sharing of contents, talking and texting with other users (Kirschner \& Karpinski 2010). Since the emergence of this new technology, researchers in the field have been trying to measure its effects with reference to users, especially, the youth around the world. They have divided people into different categories with respect to the use of digital technologies. Among such researchers Prensky (2001) reported to have used the expression of "digital natives" for the people born in the digital age. Those people who were born before them were termed by Prensky as digital immigrants. Prensky found significant differences in the two generations with regard to the usage of social media. The native are found to be very sharp and skillful in using the technology while digital immigrants are a bit alien to the use of this technology, and their thinking in line with digital technologies is thought to be outdated.

Herring (2008) also have much similar views with regard to the people born in the digital age. According to him, the people born during the 1980s decade are known as internet generation. They were brought up in a period in which internet was made available to the people, especially, in advanced countries of the world. This generation is named differently in different researches like "Net Generation," the "Net- Gen," "Generation I," the "Digital Generation," or the "Millennial." Internet generation make use of digital media for social interaction with their peers, downloading contents for their joy, fun and amusement and seek to gratify their various needs more than the people born in the preceding generation (Herring, 2008, p.71). Hence, the young people have easily adapted to and have more know-how of using digital media than their seniors with respect to age.

According to Tapscott (2009) SNSs are largely driven by young people. They by making use of these sites chat to each other, try to make new friends and keep in constant contact with their colleagues. Similarly, they can share information of their choice and interests with their friends and others through numerous web places easily accessible. As they have grown up digital so they often engage themselves in two ways trafficking of information. They have the facility to give comments on contents, audios and videos. This generation gap in terms of usability of internet is phrased by Jane, Michele \& Ellen (2002) as the "generational digital divide" or the "generational divide." 


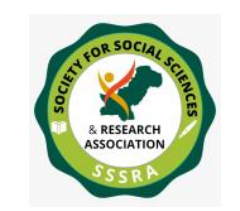

Pak. Journal of Int'L Affairs, Vol 4, Issue 3 (2021)

Genesis of Social Media and the Nature ...

Similarly, Lankshear and Bigum (1999) used the phrases like "insiders" for digital natives and "newcomers" for digital immigrants. Their differentiation between the two generations was not based on the differences in skills of using the technology but they rather thought of the differences between the two generations in terms of approaches to seeing at the technology. The insiders believed that the world was the same; the only change they thought was the presence of technology. However, the newcomers termed the world to have been changed drastically just because of the diffusion of technology into it. Some of the researchers in the area, however, believed that one cannot necessarily become skillful in using digital technologies by virtue of his/her birth in the digital age. Kennedy, et al. (2010) in a study "beyond natives and immigrants: exploring types of net generation students" found that 45 percent of the respondents knew only the rudiments of digital technology. They neither were regular users of the new technologies nor were they aware of the standardized web tools. The respondents were found to be biweekly or monthly users of classic web technologies. The findings of their study revealed that 15 percent participants were skillful users who could make use of digital technologies effectively and much to their advantages. Although digital natives are skilled users of technology but they according to Salaway \& Caruso (2007) very often confined themselves to the use of social networking and leave behind use of other features like blogging. They further noted that a very few among the young people could be termed efficient users of SNSs. A few research studies in the field like that of Livingstone (2008) found that majority of these young people born in the digital age are a bit ignorant of the usage of ICTs.

The users of SNSs have been given different names by different authors and researchers in the field on account of the way they approach to the technology. As the consumers of SNSs are the generators and contributors of contents to the same media hence they are labeled by Schafer (2009) as "Generation C" where C denotes contents. Similarly, Leadbeater, Charles, \& Miller (2004) predicted their names as "Pro-Ams" where "Pro" is used for professional and "Ams" is used for amateurs. Likewise, the rationality behind the creation of contents by the users is termed by Tapscott \& Williams (2006) as "Wikinomics". In the same manners, Bruns (2008) calls these consumers of digital technology as users and producers. He labeled the activities they do online as "produsage."

\section{Conclusion}

Since the emergence of new information communication technology (ICT), the researchers in the field have been trying to measure its effects with reference to people, especially, the youth around the world. The people who make use of these technologies 
are seemed to be the key beneficiaries. That is why some of the researchers have laid emphasis on the nature of users instead of the nature of usage. People have been divided into different categories with respect to the use of digital technologies. Prensky (2001) is reported to have used the expression of "digital natives" for the people born in the digital age. Those people who were born before them were termed by Prensky as digital immigrants. Prensky found significant differences in the two generations with regard to social media use. The digital natives are found to be very sharp and skillful in using the technology while digital immigrants are a bit alien to the use of this technology, and their thinking in line with digital technologies is thought to be outdated. According to Herring (2008), the people born during the decade of 1980s are known as internet generation. They were brought up in a period in which internet was made available to them. This generation is named differently in different researches such as "Net Generation," the "Net- Gen," "Generation I," the "Digital Generation," or the "Millennial". Hence, the young people have easily adapted to and have more know-how of using digital media than their seniors with respect to age. This generation gap in terms of usability of internet is phrased as the "generational digital divide" or the "generational divide (Jane, Michele, \& Ellen 2002). 


\section{References}

Abdulahi, Samadi, B., \& Gharleghi, B. (2014). A Study on the Negative Effects of Social Networking Sites Such as Facebook among Asia Pacific University Scholars in Malaysia. International Journal of Business and Social Science, 5 (10), 133-145.

Ahn, J. (2011). The Effect of Social Network Sites on Adolescents' Social and Academic Development: Current Theories and Controversies. Journal of the American Society for Information Science and Technology, 62(8):1435-1445.

Bargh, A. J. \& McKenna, Y. A. K (2004). The Internet and Social Life. Annual Review of Psychology, 55, 573-590.

Boomen, M. V., Lammes, S., Lehmann, A., Joost Raessens, J.,\& Schafer, M. T. (Eds 2009). Digital Material: Tracing New Media in Everyday Life and Technology. (p.7). Amsterdam University Press.

Boyd, D. \& Ellison, N. B. (2007). Social network sites: Definition, history, and scholarship. Journal of Computer Mediated Communication, 13, 210-230.

Brown, J. S., \& Adler, R. P. (2008). Minds on Fire: Open Education, the Long Tail and Learning 2.0. Educase Review, 43 (1), 28-38.

Bruns, A. (2008). Blogs, Wikipedia, Second Life, and Beyond: From Production to Produsage. New York, USA: Peter Lang.

Bryer, T. A. \& Zavattaro, S. M. (2011). Social media and public administration: Theoretical dimensions and introduction to symposium. Administrative Theory \& Praxis, 33(3), 325-340.

Castells, M. (2001). The Internet Galaxy: Reflections on the Internet, Business, and Society, Oxford, UK: Oxford University Press.

Connolly, M. (2011). Benefits and Drawbacks of Social Media in Education. Wisconsin Center for Education Research (WCER), 22 (4), 2.

Debatin, B., Lovejoy, J. P., Horn, A. K., A, M., \& Hughes, B. N. (2009). Facebook and online Privacy: Attitudes, Behaviors, and Unintended Consequences. Journal of Computer Mediated Communication, 15, 83-108. 
Facebook. (2017). Key facts. Retrieved on June 12, 2016 from: http://newsroom.fb.com/content/default.aspx ?NewsAreaId=22

Hargittai, E. (2008). Whose Space? Differences Among Users and Non-Users of Social Network Sites. Journal of Computer Mediated Communication, 13, 276-297.

Haq, U. A. \& Chand, S. (2012). Pattern of Facebook usage and its Impact on Academic Performance of University Students: A Gender Based Comparison. Bulletin of Education and Research, 34 (2), 19-28.

Hendrix, D., Chiarella, D., Hasman, L., Murphy, S., \& Zacfron, M. L. (2009). Use of Facebook in academic health sciences libraries. Journal of the Medical Library Association, 97(1), 43-46.

Herring, S. C. (2008). Questioning the Generational Divide: Technological Exoticism and Adult Constructions of Online Youth Identity. In David, B. (ed). Youth, Identity, and Digital Media, MacArthur Foundation Series on Digital Media and Learning. (pp.71-92). Cambridge, MA: The MIT Press.

Jane, K. Michele, C. \& Ellen, R. (2002). Bridging the Generation Gap Across the Digital Divide: Teens Teaching Internet Skills to Senior Citizens. Journal of Extension, 40 (3). ISSN:1077-5315.

Kennedy, G., Judd, T., Dalgarnot, B., \& Waycott, J. (2010). Beyond Natives and Immigrants: Exploring Types of Net Generation Students. Journal of Computer Assisted Learning, 26, 332-343.

Kerr, J. M. (2010). The history of Twitter. Retrieved on June 11, 2014 from: http://ezinearticles.com

Kirschner, P. A. \& Karpinski, A. C. (2010). Facebook and Academic Performance. Computers and Human Behavior. 26: 1237-1245.

Kwak, H., Lee, C., Park, H., \& Moon, S. (2010, April 26-30). What is Twitter, a social network or a news media? Presented at the International World Wide Web Conference, Raleigh, North Carolina.

Lange, P. G. (2007). Publicly private and privately public: Social networking on YouTube. Journal of Computer-Mediated Communication, 13(1), 18. 


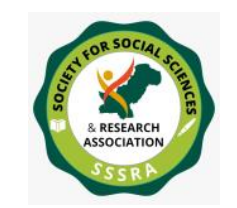

Genesis of Social Media and the Nature ...

Lankshear, C., \& Bigum, C. (1999). Literacy and New Technologies in School Settings. Pedagogy, Culture and Society, 7(3), 445-465.

Leadbeater, Charles, \& Miller, P. (2004). The Pro-am Revolution. London, UK: Demos.

Lister, M., Dovey, J., Giddings, S., Grant, I., \& Kelly, K. (2009). New media: A critical Introduction ( $2^{\text {nd }}$ ed.). New York, USA: Routledge.

Livingstone, S. (2008). Taking risky opportunities in youthful content creation: teenagers' use of social networking sites for intimacy, privacy and selfexpression. New Media \& Society, 10(3), 393-410.

Luo, J. (2007). Social Networking: Now Professionally Ready. Primary Psychiatry, 14(2), 21-24.

Mahmood, S. (2013). The Effects of Social Networking Sites on the Academic Performance of Students in College of Applied Sciences, Nizwa, Oman. International Journal of Arts and Commerce. 2 (1).

Martin, P. \& Erickson, T. (2013). Social Media: Usage and Impact. New Delhi, India: Global Vision Publishing House.

McLuhan, M. (1964). Understanding Media. New York, USA: Mentor. Cited in West, R. \& Turner, L. H. (2007). Introducing Communication Theory: Analysis and Application. (3 ${ }^{\text {rd }}$ ed., 460-491). New York, USA: McGraw-Hill.

Miniwatts Marketing Group. (2017). Internet World Stats: Population and Internet Users, Retrieved on June 15, 2014 from: www.internetworldstats.com

Moody, M. (2010). Teaching Twitter and Beyond: Tips for incorporating social media in traditional courses. Journal of Magazine and New Media Research, 11 (2), 1 - 9.

Murugesan, S. (2007), Understanding Web 2.0. IT Professional, 9 (4), 34-41.

Packard, A. (2010). Digital Media Law. London, UK. Willey Blackwell.

Papacharissi, Z. (2009). The virtual geographies of social networks: A comparative analysis of Facebook, LinkedIn, and Asmallworld. New Media \& Society, 11(1), 199-220. 
Pempek, T. A., Yermolayeva, Y. A., \& Calvert, S. L. (2009). College students' social networking experiences on Facebook. Journal of Applied Developmental Psychology, 30(3), 227-238.

Prensky, M. (2001). Digital Natives, Digital Immigrants. On The Horizon, 9(5), 1-6.

Safko, L. (2012). The Social Media Bible: Tactics, Tools \& Strategies For Business Success. ( $3^{\text {rd }}$ ed., 31. 32). New Jersey, USA: Wiley \& Sons.

Salaway, G., \& Caruso, J. B. (2007). The ECAR study of undergraduate students and information technology, 2007. EDUCAUSE. Retrieved April 22, 2008, from http://www.educause.edu/content.asp?PAGE_ID=13903\&bhcp=1.

Schafer, M. T. (2009). Participation inside:User activities between design and appropriation. In Boomen, M. V., Lammes, S., Lehmann, A., Joost Raessens, J.,\& Schafer, M. T. (eds., 147). Digital Material: Tracing New Media in Everyday Life and Technology. Amsterdam University Press.

Smith, A., \& Rainie, L. (2008). The Internet and the 2008 Election. Pew Internet \& American Life Project. Washington, DC: Pew Trust. Retrieved form http://www.pewinternet.org/

Tapscott, D. (2009). Grown up Digital: The Net Generation as Consumers. USA: McGraw Hill.

Tapscott, D. \& Williams, A. D. (2006). Wikinomics: How Mass Collaboration Changes Everything. New York, USA: Portfolio.

Uricchio, W. (2009). Moving Beyond the Artefact: Lessons from Participatory Culture. In Boomen, M. V., Lammes, S., Lehmann, A., Joost Raessens, J., \& Schafer, M. T. (eds., 138). Digital Material: Tracing New Media in Everyday Life and Technology. Netherland: Amsterdam University Press.

Walther, J. B., Van Der Heide, B., Kim, S. Y., Westerman, D., \& Tong, S. T. (2008). The role of friends' appearance and behavior on evaluations of individuals on Facebook: Are we known by the company we keep? Human Communication Research, 34(1), 28-49.

Williams, D. L., Crittenden, V. L., Keo, T. \& McCarty, P. (2012). The use of social media: an exploratory study of uses among digital natives. Journal of Public Affairs, 12 (2), 127-136. 